\title{
Arterial Embolism in Malignancy: The Role of Surgery
}

\author{
Patrick Harnarayan' \\ Shariful Islam² \\ Vijay Naraynsingh ${ }^{3}$
}

'Department of Clinical Surgical Sciences, University of the West Indies, St. Augustine, Trinidad and Tobago; ${ }^{2}$ Department of Surgery, San Fernando General \& Teaching Hospitals, San Fernando, Trinidad and Tobago; ${ }^{3}$ Department of Surgery, Medical Associates Hospital, St. Joseph, Trinidad and Tobago
Correspondence: Patrick Harnarayan Email patrick_harnarayan@hotmail.com
Background: Peripheral arterial embolism from malignant disease is uncommon and a rare cause of limb ischemia. In the acute setting, patients can present with severe ischemia of either the upper or lower limb, and urgent surgical intervention is often required to avoid severe debilitation and limb loss.

Patients: Our case series comprised three patients who presented with upper and lower limb ischemia and were found to have concomitant malignancy. All three patients were female, with a median age of 54.3 years, and none of the patients was on active chemotherapy. One presented with stage IIb uterine carcinoma, one with stage IIIb ovarian carcinoma, and the other with stage IIIb cervical carcinoma. These patients were referred for vascular management, with two being acute and the other acute on chronic.

Results: Of the three patients, two presented with acute limb ischemia and underwent arterial thrombectomy, one of the upper and the other the lower limb. The third patient, with acute-onchronic upper limb ischemia, was treated conservatively with intravenous heparin followed by oral anticoagulation. All three had limb salvage and survival outcome at 1 year post-treatment. Conclusion: In this small series, surgical intervention in two patients and conservative management in the other patient led to limb salvage with a reasonably good quality of life. Even though the long-term survival for patients with malignant disease is generally poor, surgical intervention can achieve limb salvage with a reasonably good quality of life.

Keywords: arterial embolism, malignancy, limb salvage, quality of life

\section{Introduction}

Peripheral arterial embolism or thrombosis from malignant disease is uncommon and a rare cause of acute limb ischemia. ${ }^{1}$ Pathologically, tumor embolism is defined as a cluster of tumor cells within the arterial system not contiguous with locally advanced or metastatic disease, producing flow disturbances. ${ }^{2}$ Limb ischemia can be caused by emboli from the tumor itself, from metastatic deposits within large vessels, as well as the tumors of adjacent organs such as the lung, which invade the left or right atrium of the heart and then disseminate to the main arteries of the body. ${ }^{3}$ This acute event may be the first indication of malignant disease in the patient. ${ }^{4}$ Herein, we present three patients diagnosed with malignant disease presenting with limb ischemia. We discuss the mechanisms associated with arterial embolism and thrombosis, the implications of surgical intervention, and the immediate and 1-year outcomes after treatment.

\section{Patients}

Three patients who presented with upper and lower limb ischemia were found to have concomitant malignancy. All three patients were female, with a median age of 54.3 


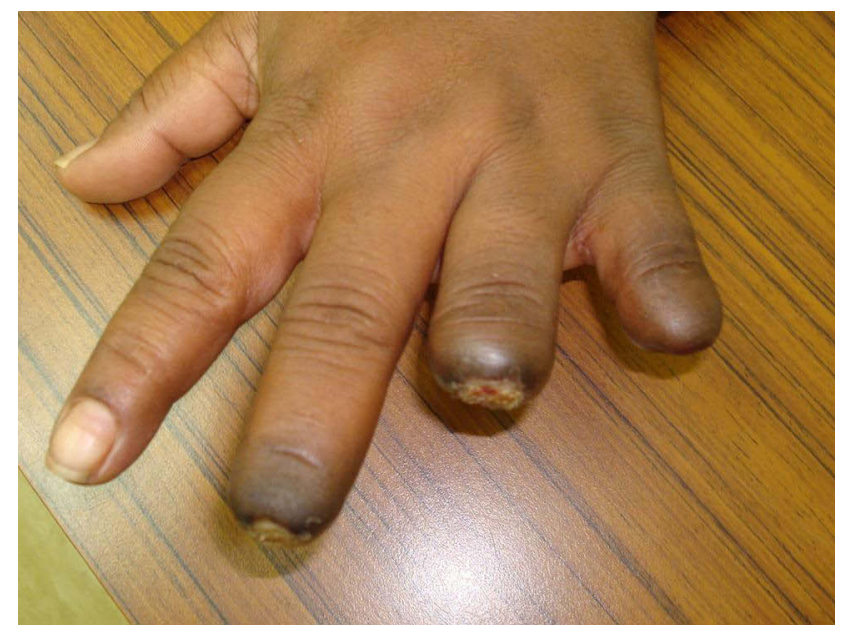

Figure I Patient I: Left hand, dorsal view, showing ischemia with autolysis of the middle, ring, and little fingers.

years. One presented with stage IIb uterine carcinoma, one with stage IIIb ovarian carcinoma, and the other with stage IIIb cervical carcinoma. None of the patients was on active chemotherapy. These patients were referred for vascular management, with two being acute and the other acute on chronic.

\section{Patient I}

A 55-year-old schoolteacher, who had been diagnosed with and treated for locally disseminated uterine malignancy (stage IIb), presented to the vascular clinic with ischemic fingers of her left hand. She had the appearance of ischemia due to embolization to the finger tips, and these became gangrenous over the next 4-6 weeks and progressed with some degree of autolysis (Figure 1). She was investigated initially with a transthoracic echocardiogram but this showed no intracardiac thrombus or abnormal wall contractility. Magnetic resonance (MR) angiography showed no proximal lesions but revealed severe forearm embolization along both radial and ulnar arteries (Figure 2).

She was treated conservatively, kept on oral anticoagulation, and followed in the outpatient clinic. She had selflimiting changes and autolysis of the distal aspect of her digits, remained on oral anticoagulation with a reasonable good quality of life, and returned to her teaching profession. She was followed up for 18 months but eventually started feeling weaker than before; she stopped teaching and finally stopped coming to clinic. We learned that she had died. The interval from time of diagnosis to time of presentation with arterial thrombosis was 18 months. She received no active treatment.

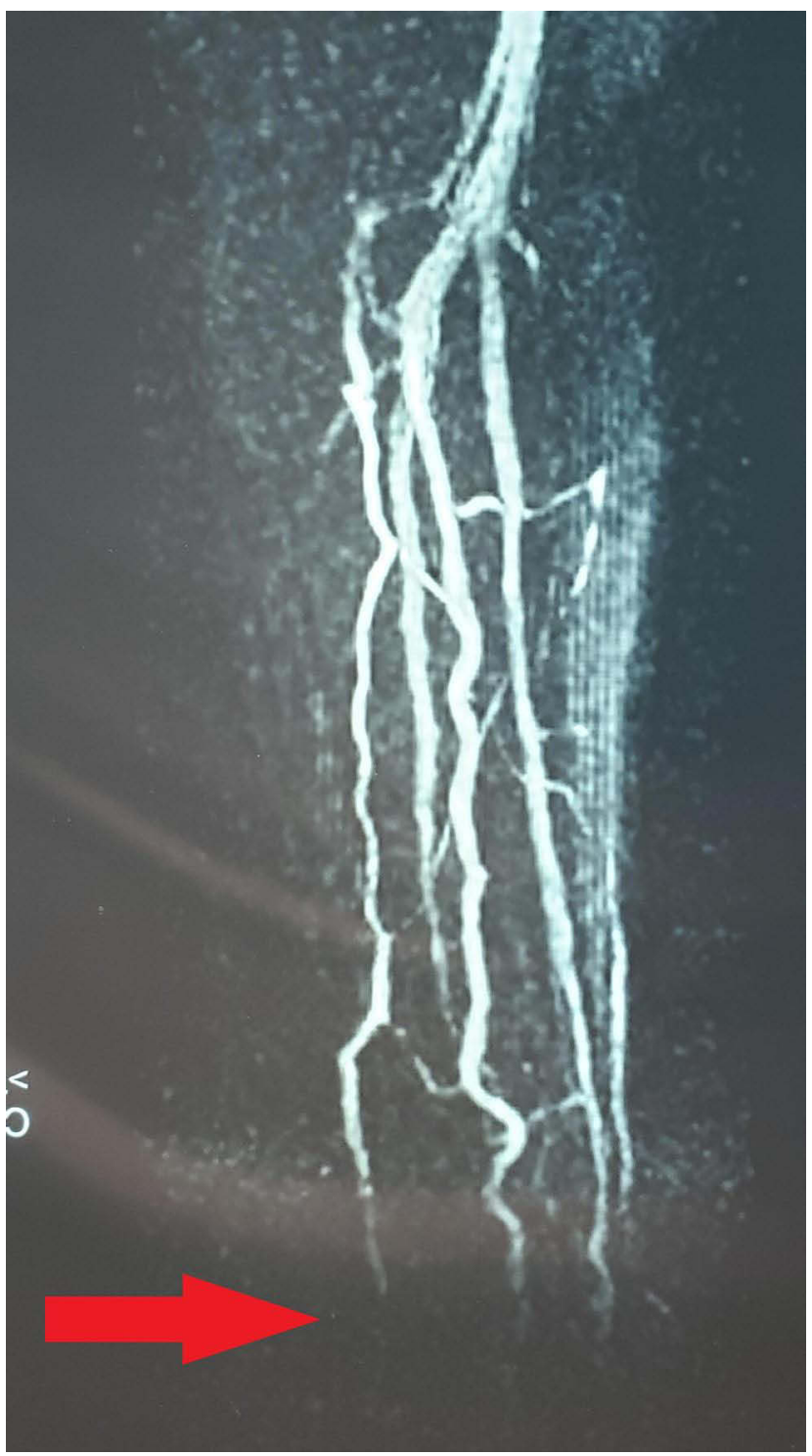

Figure 2 Patient I: Left upper limb angiogram showing embolization to distal forearm vessels.

\section{Patient 2}

A 50-year-old female patient, who had undergone surgery earlier on the same day for an ovarian mass strongly suggestive of malignancy, presented with an ischemic left leg later that day. The left femoral, popliteal, dorsalis pedis, and posterior tibial pulses were absent, and the leg was cold and painful. All contralateral pulses were present and she was given thromboprophylaxis prior to surgery. An MR angiogram showed a clear filling defect in the left proximal external iliac artery (Figure 3 ). She was diagnosed as having an acute thrombotic event, taken to the operating suite, and underwent a left femoral retrograde thrombectomy which retrieved a 3-4 cm thrombus. She regained circulation to the 


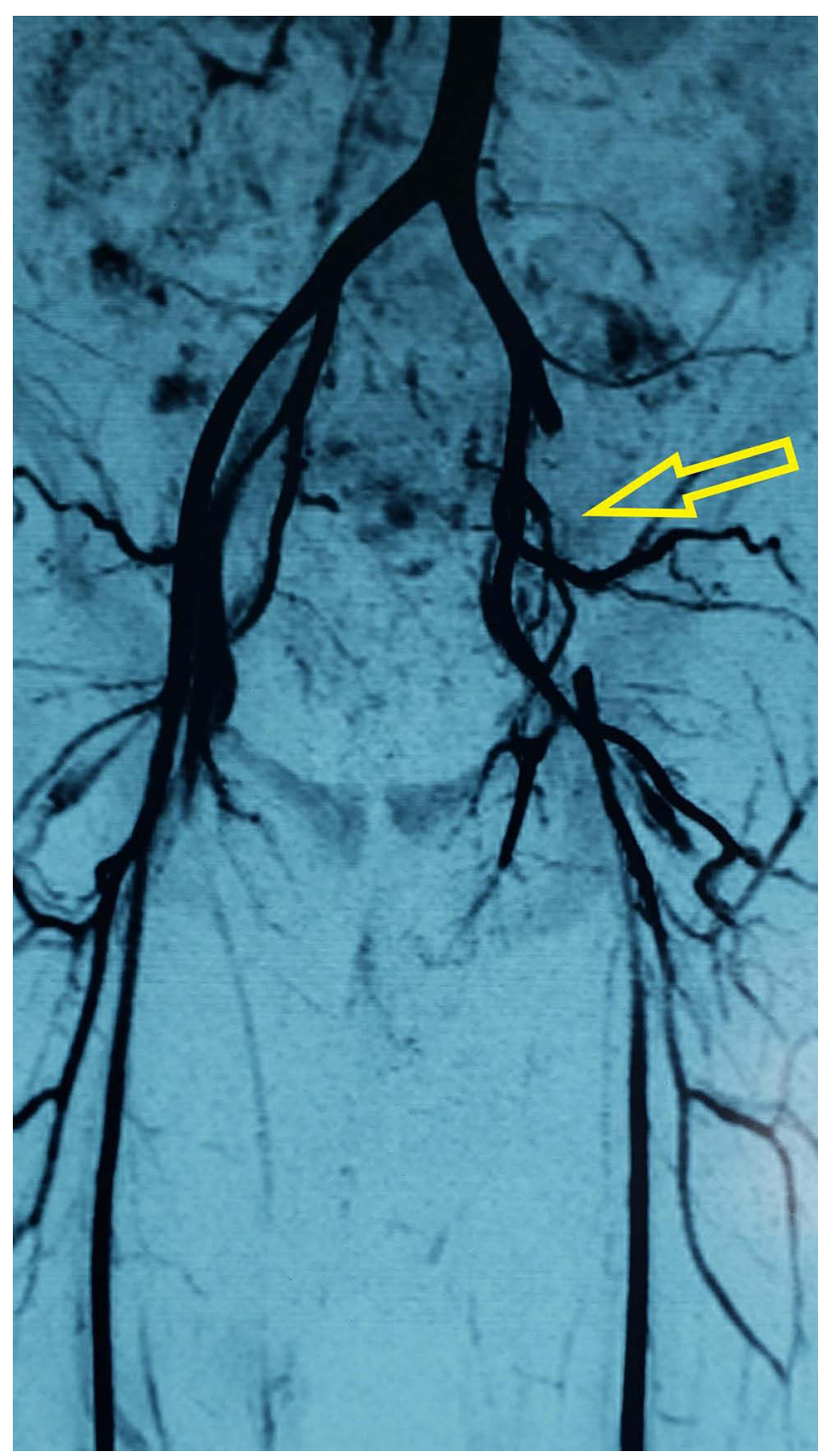

Figure 3 Patient 2: Angiogram showing left external iliac artery occlusion.

left leg with return of pulses and was fully anticoagulated, but the distal aspect of her toes remained dusky. This was self-limiting and non-progressive, with the tips of the terminal phalanges displaying dry gangrene. She was diagnosed as having stage IIIb ovarian carcinoma and was managed by the oncological gynecology team. She was discharged on oral anticoagulation (warfarin) and followed up in the outpatient clinic.

The dry gangrenous patches of her toes remained and these were allowed to demarcate and eventually autolysed. At first, she was wheelchair-bound; then, she was able to stand and walk with the aid of a walking stick and appeared to have a reasonably good quality of life. She was followed for 12 months, and managed by her oncology gynecology team thereafter, but died from advanced carcinoma 1 year later. The interval from time of diagnosis to time of presentation with arterial thrombosis was 2 weeks, and treatment had not yet started for this patient.

\section{Patient 3}

A 58-year-old patient, who had been diagnosed and treated for stage IIIb cervical carcinoma 18 months previously, presented with a severely ischemic right hand. Owing to the severe ischemic changes in her hand she was immediately taken to the operating theatre for right brachial artery embolectomy, since ultrasound interrogation showed decreased flow in the distal brachial artery with appearances suggestive of an embolus.

The patient underwent a brachial embolectomy, with significant thrombus being retrieved. The hand was reperfused, with palpable brachial and wrist pulses. However, later that day, the patient was returned to operating theatre owing to a recurrence of the ischemic changes seen at presentation. A redo thromboembolectomy was performed, with thrombus retrieval. Her hand was reperfused after the repeat procedure and remained so after surgery. Over the next 24 hours, her hand became progressively cyanotic with reduced wrist pulses. A further (third) thromboembolectomy was carried out, with thrombus retrieval and good postoperative perfusion. She remained on intravenous coagulation and, once the hand remained well perfused, she was converted to oral anticoagulation.

Because of the recurrent nature of her presentation, she was investigated further with a transthoracic echocardiogram, which showed no intracardiac thrombus, and MR angiography, which demonstrated thrombus at the level of the axillary artery (Figure 4), suggesting that there may have been embolization from this thrombotic lesion. She was kept on oral anticoagulation (warfarin) and followed up in the outpatient clinic.

She was initially seen in clinic with a well-perfused hand but was lost to follow-up after 6 months. She was not known to be on any anticoagulants thereafter and was not seen after the 1-year post-surgery mark. She was readmitted more than 1 year after discharge with an ischemic right hand, but in a terminal state from metastatic disease, and was treated with palliation.

The interval from the time of diagnosis to time of presentation with arterial thrombosis was 12 months, with treatment (surgery, chemotherapy, and radiation) having been completed, the last 3 months previously. She was therefore on no active treatment at the time of presentation. 


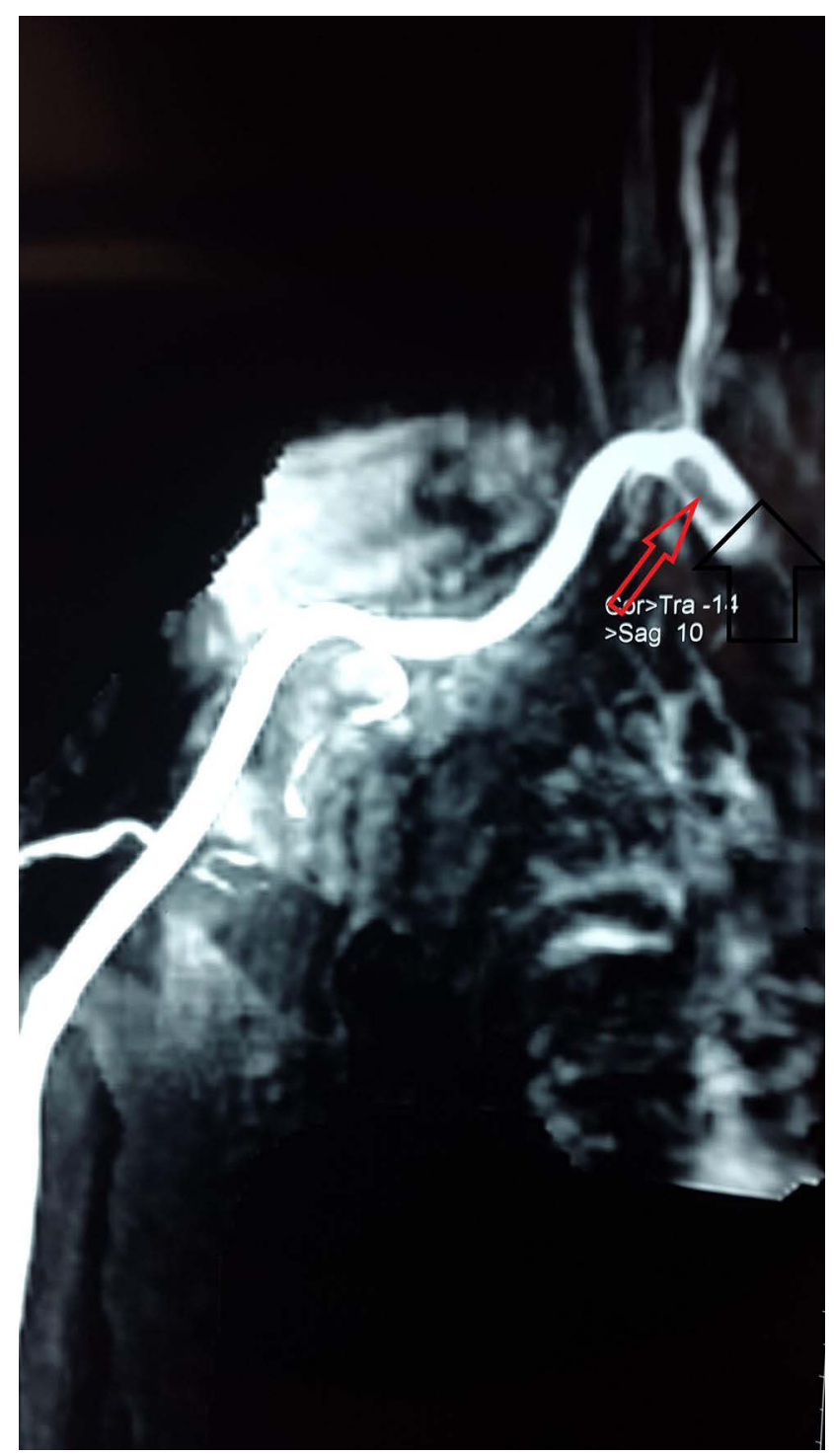

Figure 4 Patient 3: Thrombus load, right axillary artery.

The two patients who had surgery both achieved satisfactory short- and mid-term results. All three patients were alive after 1 year, and two after 2 years, but unfortunately none survived to meet their 3-year follow-up. The thrombotic material retrieved from the arteries of these patients was sent off for analysis and confirmed to be thrombus, but no tumor cells were identified in the specimens.

\section{Discussion}

Arterial thromboembolism was once thought to be quite rare, but the reported rate varies between $11.7 \%$ of critical limb ischemia patients ${ }^{5}$ and $16 \%$ of all acute limb ischemia with occult malignancy. ${ }^{6}$ It can present with cardiac, splenic, and renal infarcts, as well as ischemic strokes ${ }^{7}$ and vessel occlusion in either upper or lower limbs., ${ }^{8,9}$ The vessels most commonly involved are the superficial femoral, the brachial, and the popliteal arteries, ${ }^{10}$ and this is sometimes the first indication of malignancy in a young patient. ${ }^{3}$

The most common malignancies reported to cause arterial occlusion are lung carcinomas, ${ }^{10,11}$ breast carcinoma, ${ }^{12}$ renal (Wilms' and renal cell) carcinomas, hepatocellular $^{13}$ and cholangiocarcinomas, ${ }^{14,15}$ uterine carcinomas, ${ }^{16}$ and melanomas. ${ }^{4}$ Cervical carcinoma, though uncommon, can invade the right ventricle and embolize to the periphery. ${ }^{17}$ Evidence from autopsy specimens suggests that tumors arising from the lung, ovary, kidney, and liver had greater likelihood for tumor embolism. ${ }^{18}$ Histology of these lesions can show malignant cells reflecting the exact type of the patient's existing lesion, ${ }^{9}$ but specimens may yield thrombus with no tumor cells being identified. ${ }^{10}$

Active chemotherapy can be an inciting factor, especially in patients who receive adjuvant chemotherapy for breast carcinoma, ${ }^{19}$ with a high number of patients presenting with arterial thromboses and arterial occlusive disease while undergoing chemotherapy. ${ }^{10,12}$ The platinum-based agents, when given intravenously, have vaso-occlusive effects, causing severe lower limb arterial disease, especially in young patients. ${ }^{20,21}$

Although the mechanism of tumor embolism is unknown, malignancy can be considered an acquired thrombophilic state ${ }^{22}$ and this is greatest in the first few months after diagnosis and in those with distant metastatic disease. $^{23}$ Malignant cells can activate the coagulation cascade and cause thromboses as well as inhibit anticoagulant activity of the vascular endothelium. ${ }^{22}$ For instance, pancreatic cancer cells can activate platelets to produce procoagulants, including thrombin and tissue factor, which is increased in patients with malignancy. ${ }^{24,25}$

Thrombosis from malignancy clearly worsens the overall prognosis of patients, ${ }^{13}$ but good outcomes have been reported in some studies. In one series of 16 patients $(50 \%$ were recent) in which all patients had surgical intervention (14 embolectomies and two bypasses), there was a $37.5 \%$ limb loss (six limbs) and a mortality rate of only $12.5 \%$, and $44 \%$ were still alive at 1 -year follow-up. ${ }^{10}$ In another series with 24 patients, there were similar perioperative mortality rates for both malignant and non-malignant patients $(20 \%$ vs $16 \%)$ and limb salvage at 30 months (95\% vs 89\%); although long-term survival was less ( $45 \%$ vs $77 \%$ ), the authors advocated surgery as a viable option in these patients. ${ }^{26}$ 
Warfarin (Coumadin $\AA$ ), used as monotherapy, was our choice of anticoagulation because of its wide availability, low cost, and easy monitoring at outpatient clinic level, as well as its effective anticoagulant properties. Alternatively, owing to their increased accessibility, the novel oral anticoagulants are also efficacious and can be used.

\section{Conclusion}

Although arterial embolism due to malignancy is uncommon, it is important to have a high index of suspicion, especially in young patients and in those recently diagnosed with malignant disease. Surgical intervention can be rewarded with reasonably good short- and medium-term quality-of-life benefits and can be considered a good treatment option in acute cases.

\section{Ethical Approval}

Ethical approval is required at our institutions only for experimental work using human subjects.

\section{Consent}

All three patients initially consented to have their cases used in a case series (which was what was required at that time) and also gave all radiological material to the authors to keep for research and teaching purposes. All three were considered for written consent at about the time this manuscript was being thought out, but when reviewed they were, by then, in a terminal state and it was not thought to be correct to seek written permission at that time. Verbal consent is all that can be obtained from the nearest relatives at this point in time owing to the movement restrictions placed on us by the COVID-19 pandemic lockdown. All consents have been obtained in good faith from patients/family with a knowledge of publication for teaching purposes.

\section{Acknowledgments}

The authors have no acknowledgements to make.

\section{Author Contributions}

All authors made a significant contribution to the work reported, whether that is in the conception, study design, execution, acquisition of data, analysis and interpretation, or in all these areas; took part in drafting, revising or critically reviewing the article; gave final approval of the version to be published; have agreed on the journal to which the article has been submitted; and agreed to be accountable for all aspects of the work.

\section{Funding}

The authors received no funding for this article.

\section{Disclosure}

The authors reported no conflicts of interest for this work.

\section{References}

1. Morsey H, Aslam M, Standfield N. Tumor embolization causing acute ischemia with sometimes fatal results. Case report and review of literature. Int Angiol. 2004;23(1):82-84.

2. Tang MH, Lim J, Bushmani I, Ng CY. An unusual case of ovarian carcinomatosis with microscopic tumor embolism leading to rectal ischemia and perforation. Clin Endosc. 2018;51(3):294-298. doi: $10.5946 /$ ce. 2017.152

3. Singh A, Jenkins DP, Dahdal M, Dhar S, Ratnatunga CP. Recurrent arterial embolization/from a metastatic germ cell tumor invading the left atrium. Ann Thorac Surg. 2000;70(6):2155-2156. doi:10.1016/ S0003-4975(00)01899-3

4. Ramchandani P, Morris MC, Zeit RM. Acute limb ischemia due to arterial embolism of tumor. Case reports. Cardiovasc Intervent Radiol. 1990;13(6):372-374. doi:10.1007/BF02578678

5. Sundbøll J, Veres K, Horváth-Puhó E, Adelborg K, Sørensen HT. Risk and prognosis of cancer after lower limb arterial thrombosis. Circulation. 2018;138(7):669-677. doi:10.1161/CIRCULATIO NAHA.117.032617

6. El Sakka K, Gambhir RPS, Halawa M, Chong P, Rashid H. Association of malignant disease with critical leg ischaemia. $\mathrm{Br}$ J Surg. 2005;92:1498-1501. doi:10.1002/bjs.5125

7. Morasch MD, Shanik GD. Tumor embolus: a case report and review of literature. Ann Vasc Surg. 2003;17:210-213. doi:10.1007/s10016001-0251-0

8. Sadat U, Noor N, See TC, Varty K. Peripheral arterial ischemia by primary lung tumour invading left atrium. Lung Cancer. 2007;57:237-239. doi:10.1016/j.lungcan.2007.02.001

9. Schreffler SS, Paolo WF, Kloss BT. Spontaneous showering of tumor emboli in a patient with advanced primary lung cancer: a case report. Int J Emerg Med. 2012;5. Article number: 27. doi:10.1186/18651380-5-27

10. Tsang JS, Naughton PA, O'Donnell J, Moneley DS, Kelly CJ, Leahy AL. Acute Limb ischemia in cancer patients: should we surgically intervene? Ann Vasc Surg. 2011;25(7):954-960. doi:10.1016/j.avsg.2011.06.002

11. Stein ME, Drumea K, Ben-Itshak O, et al. Acute limb ischemia due to malignant arterial embolism from a metastatic germ cell tumor. Med Pediatr Oncol. 1995;25(2):126-129. doi:10.1002/mpo.2950250216

12. Javid M, Magee TR, Galland RB. Arterial thrombosis associated with malignant disease open archive. Eur J Vasc Endovasc Surg. 2008;35:84-87. doi:10.1016/j.ejvs.2007.08.014

13. Quencer KB, Friedman T, Sheth R, Oklu R. Tumor thrombus: incidence, imaging, prognosis and treatment. Cardiovasc Diagn Ther. 2017;7(Suppl 3):S165-S177. doi:10.21037/cdt.2017.09.16

14. Ching CK. Trousseau's syndrome in a patient with cholangiocarcinoma. Am J Gastroenterol. 1991;86(7):928-929.

15. Blum MF, Ma VY, Betbadal AM, Bonomo RA, Raju RR, Packer CD. Trousseau's syndrome in cholangiocarcinoma: the risk of making the diagnosis. Clin Med Res. 2016;14(1):53-59. doi:10.3121/ cmr.2015.1304

16. Dzieciuchowicz LS, Slowinski M, Brzezinski JJ, Kycler W. Tumor embolus due to uterine cancer. Med Sci Monit. 2009;15(10):CS155-157.

17. Han GH, Kwon DY, Ulak R, Ki KD, Lee J-M, Lee S-K. Right ventricular metastatic tumor from a primary carcinoma of uterine cervix: a cause of pulmonary embolism case report. Obstet Gynecol Sci. 2017;60(1):129-132. doi:10.5468/ogs.2017.60.1.129 
18. Sakuma M, Fukui S, Nakamura M, et al. Cancer and pulmonary embolism: thrombotic embolism, tumor embolism, and tumor invasion into a large vein. Circ J. 2006;70:744-749. doi:10.1253/ circj. 70.744

19. Saphner T, Tormey DC, Gray R. Venous and arterial thrombosis in patients who received adjuvant therapy for breast cancer. J Clin Oncol. 1991;9(2):286-9430. doi:10.1200/JCO.1991.9.2.286

20. Numico G, Garrone O, Dongiovanni V. Prospective evaluation of major vascular events in patients with nonsmall cell lung carcinoma treated with cisplatin and gemcitabine. Cancer. 2005;103:994-999. doi:10.1002/cncr.20893

21. Doll DC, List AF, Greco FA, Hainsworth JD, Hande KR, Johnson DH. Acute vascular ischemic events after cisplatin-based combination chemotherapy for germ-cell tumours of the testis. Ann Intern Med. 1986;105:48-51. doi:10.7326/0003-4819-105-1-48

22. Falanga A, Rickles FR. Pathophysiology of the thrombophilic state in the cancer patient. Semin Thromb Hemost. 1999;25(2):173-182. doi:10.1055/s-2007-994919
23. Blom JW, Doggen CJ, Osanto S, Rosendaal FR. Malignancies, prothrombotic mutations, and the risk of venous thrombosis. JAMA. 2005;293:715-722. doi:10.1001/jama.293.6.715

24. Kakkar AK, DeRuvo N, Chinswangwatanakul V, Tebbutt S, Williamson R. Extrinsic-pathway activation in cancer with high factor VIIa and tissue factor. Lancet. 1995;346(8981):1004-1005. doi:10.1016/S0140-6736(95)91690-3

25. Khorana AA, Fine RL. Pancreatic cancer and thromboembolic disease. Lancet Oncol. 2004;5(11):655-663. doi:10.1016/S14702045(04)01606-7

26. Silverberg D, Yalon T, Reinitz ER, Yakubovitch D, Segev T, Halak M. Acute limb ischemia in cancer patients: aggressive treatment is justified. Vascular. 2015;23(1):55-60. doi:10.1177/ 1708538114537048

\section{Publish your work in this journal}

Therapeutics and Clinical Risk Management is an international, peerreviewed journal of clinical therapeutics and risk management, focusing on concise rapid reporting of clinical studies in all therapeutic areas, outcomes, safety, and programs for the effective, safe, and sustained use of medicines. This journal is indexed on PubMed Central, CAS,
EMBase, Scopus and the Elsevier Bibliographic databases. The manuscript management system is completely online and includes a very quick and fair peer-review system, which is all easy to use. Visit http://www.dovepress.com/testimonials.php to read real quotes from published authors 